\title{
Prevalence Of Trichomonas Vaginalis Among Pregnant Women Attending Hospital In Irrua Specialist Teaching Hospital In Edo State, Nigeria
}

\author{
Ochei Kingsley Chinedum ${ }^{1}$, Obeagu Emmanuel ifeanyi ${ }^{2}$, \\ Ugwu Getrude Uzoma ${ }^{3}$, George Christiana Ngozi ${ }^{2}$ \\ 1. Department of Medical Laborator Sciences, Facaulty of Basic Medicine, Ambrose Ali University Ekpoma, \\ Edo State, Nigeria. \\ 2. Diagnostic Laboratory Unit, University Health Services Department, Michael Okpara University of \\ Agriculture, Umudike, Abia State, Nigeria. \\ 3. Department of Nursing Science, ESUT Teaching Hospital, Parklane, Enugu, Enugu State, Nigeria.
}

\begin{abstract}
This study was done on the prevalence of Trichomonas vaginalis among pregant women attending Irrua Specialist Teaching Hospital, Edo. The study was done to ascertain the prevalence level among those women. T. vaginalis is a common sexually transmitted infection among sexually active women with its attendant complications especially to these women whose immune systems are not too robust.The study was done among pregant women attending the above hospital.The study showed that the pregnant women in that hospital were not infected with T.vaginalis which could be traceable to improved healthy living.
\end{abstract}

Keywords:Trichomonas vaginalis, Pregnant women,Complication of Trichomonas vaginalis, Epidemiology of Trichomonas vaginalis.

\section{Introduction}

Trichomoniasis has emerged to be one of the most common sexually transmitted infections [1]. It is caused by a flagellated protozoan parasite called Trichomonas vaginalis [1,2 and 3]. T. vaginalis trophozoite is an oval, flagellated parasite with five flagella arising near a cytosome with a conspicuous barb-like axostyle project which may be used for attachment to surfaces and may also cause the tissue damage noted in trichomoniasis infections [4, 5, 6 and 7]. T. vaginalis trophozoite is among the most durable protozoan organisms that can survive for up to 24 hours in urine, semen or even in water samples and has the ability to persist on formites with a moist surface for up to one or two hours [8 and 9]. The disease is characterized in female patients by frothy-greenish-foul smelling vaginal discharge accompanied with vulvo-vaginal irritation, dysuria and lower abdominal pains [10 and 11]. These symptoms are usually aggravated during menses and pregnancy. Other complications include cystitis, cervicitis and urethritis [12 and 13]. Reports have implicated Trichomonas vaginalis in upper reproductive tract post surgical infections, reversible infertility, low birth weight, preterm labour, neonatal morbidity and mortality [14 and 15]. Neonatal trichomoniasis can be acquired during passage through an infected birth canal. It is estimated that 2 to $17 \%$ of female babies acquire trichomoniasis through direct vulvo-vaginal contamination. It has also been incriminated as a cofactor in the transmission of HIV [16 and 17]. It has been reported that Trichomonas vaginalis causes discomfort and psychosocial distress in infected patients. Trichomoniasis is also reported to be a major cause of pathology in obsterics and gynaecology [19 and 20]. The disease is primarily transmitted through sexual contact, but contaminated formites such as towels and clothing have been implicated in the transmission [20]. The incidence of trichomoniasis depends on the population screened/examined. Certain factors such as poor personal hygiene, multiple sex partners, low socio-economic status and underdevelopment are associated with high incidence of infection [21]. Trichomonas vaginalis has been described as a common cosmopolitan parasite of both males and females. Approximately 180 million people are infected world-wide yearly, while in the United States of America, 5 million women and 1 million men are infected annually [22] rates of 5\% have been reported in asymptomatic patients attending family planning clinics, $50-75 \%$ in Commercial Sex Workers, and 0.9 to $39.6 \%$ in sexually transmitted infection clinics [23].

Trichomonas vaginalis is detectable in vaginal, prostatic or urethral secretions, semen and urine of infected individuals [24]. The most commonly employed diagnostic methods are: direct microscopic examinations of wet mount preparations [25] (sensitivity of microscopic observations varies from $38 \%-82 \%$ ), and culture techniques. Other methods include antigen detection methods, plastic envelope method, in-pouch system, cell culture, staining techniques, serological and DNA techniques [26]. Direct examination of wet mount preparation of clinical specimen is the most rapid, most commonly used and least expensive technique for identifying Trichomonas vaginalis [27]. This method has however been reported insensitive for the diagnosis of 
the disease, particularly in male patients [28 and 29]. The broth culture technique is more sensitive and valuable especially when the organisms are few- in fact, culture of the organism using vaginal specimens is the current "gold standard" [30, 31, 32, 33 and 34]. Although Polymerase Chain Reaction (PCR) techniques are currently being designed, combination of both wet mount examination and culture has been recommended as being more effective in establishing diagnosis than either one alone [35].

\section{AIM AND OBJECTIVES}

The aim of this study was to determine the prevalence of trichomoniasis among pregnant women in attending the antenatal clinic of Irrua specialist Teaching Hospital, Irrua.

The specific objectives include;

1. To determine the prevalence of trichomoniasis among pregnant women according to their trimesters.

2. To determine the age distribution of trichomoniasis among pregnant women.

3. To determine the prevalence of trichomoniasis by the marital status of the pregnant women.

\section{STUDY AREA}

\section{Materials And Methods}

The study was carried out in Irrua. It is a town in Edo State. Irrua is the headquarter of the Esan Central Local Government of Edo State. It is located on Latitude, $6^{\circ} 45^{\prime} 01^{\prime \prime} \mathrm{N}$ and Longitude $6^{\circ} 15^{\prime} 48^{\prime \prime} \mathrm{E}$. The principal inhabitants of Irrua are Esan and the major occupations are farming, trading and civil service. The Irrua Specialist Hospital, which is a federal teaching hospital is found in Irrua and is poised to carry out tertiary health care services. The total population of Irrua is about five thousand $(5,000)$.

\section{SELECTION OF SUBJECTS}

Subjects will be selected by using their hospital case file to detect their last menstrual period (LMP) which will be clearly stated in their case files. LMP will be used in categorizing subjects into their various trimesters. Information on age and marital status will obtained from the selected subjects. One hundred and fifty subjects were recruited into this study. This pregnant women will be classified into first, second and third trimester. They will also be classified into age groups and marital status.

\section{SAMPLE COLLECTION AND PREPARATION}

About $5 \mathrm{ml}$ of urine will be obtained from each pregnant women by giving them a sterile universal container inorder to void an adequate quantity of urine into it. The urine sample will be put in a centrifuge and spun at 3,500 rpm for 5 minutes. The urine deposits will be examined microscopically by wet mount preparations.

\section{PROCEDURE FOR WET MOUNT PREPARATION AND EXAMINATION}

- A clean-grease slide will be gotten

- A drop of the urine deposits will be placed on a clean grease-free slide

- A cover slip will be gently placed on the urine deposit and bubble formation will be avoided.

- The preparation will be examined for motile flagellates under the microscope using $x 40$ objective.

\section{STATISTICAL ANALYSIS}

Statistical analysis of the results will be conducted using Chi-square at $0.05 \%$ with an appropriate degree of freedom. A P-value of a level less than $0.05(\mathrm{P} \leq 0.05)$ was considered statistically significant.

\section{Results}

All the 180 urine samples examined were negative for Trichomonas vaginalis. The prevalence rate of the disease was $0 \%$.

Table 1 showed that all pregnant women in the age groups were all found negative for $\mathrm{T}$ vaginalis infection.

Table 2 showed that there was no occurrence of Trichomonas vaginalis among the pregnant women according to their trimesters

Table 3 showed that all pregnant women in respect to their levels of education were found negative to $T$ vaginalis infection.

Table 1: Age specific distribution of T. vaginalis among pregnant women

\begin{tabular}{llll}
\hline Age groups (years) & No Examined & No Positive & \% Positive \\
\hline $15-20$ & 20 & 0 & $0 \%$ \\
$21-25$ & 62 & 0 & $0 \%$ \\
$26-30$ & 50 & 0 & $0 \%$ \\
$31-35$ & 32 & 0 & $0 \%$ \\
$36-40$ & 16 & 0 & $0 \%$ \\
Total & $\mathbf{1 8 0}$ & $\mathbf{0}$ & $\mathbf{0 \%}$ \\
\hline
\end{tabular}


Table 2: Prevalence of $T$. vaginalis with reference to trimester among pregnant women

\begin{tabular}{llll}
\hline Trimester & No Examined & No Positive & \% Positive \\
\hline First & 19 & 0 & $0 \%$ \\
Second & 98 & 0 & $0 \%$ \\
Third & 63 & 0 & $0 \%$ \\
Total & 180 & 0 & $0 \%$ \\
\hline
\end{tabular}

Table 3: Prevalence of $T$. vaginalis with reference to literacy level among pregnant women

\begin{tabular}{llll}
\hline Literacy Level & No Examined & No Positive & \% Positive \\
\hline Non-Literate & 56 & 0 & $0 \%$ \\
Primary & 64 & 0 & $0 \%$ \\
Secondary & 32 & 0 & $0 \%$ \\
Tertiary & 28 & 0 & $0 \%$ \\
Total & 180 & 0 & $0 \%$ \\
\hline
\end{tabular}

\section{Discussion}

Trichomoniasis is of worldwide occurrence and shows diversity with respect to socio-cultural status of the communities changing from one country to another and from one society to another [36]. Its infection in pregnant women predisposes them to high risk of adverse birth outcomes [37 and 38]

In this study, the overall prevalence of $\mathrm{T}$. vaginalis was $0 \%$ (Tables 1-3). There were no age, trimester and literacy level prevalence of $\mathrm{T}$. vaginalis among the pregnant women. The prevalence observed in this study appeared to suggest the non-existence of relatively high rate of this infection among pregnant women attending Irrua Specialist Teaching Hospital which in effect indicates that the organism is not present in the population. It further suggests that trichomoniasis may have been the focus of intense study or active control programs have been established towards the nature of the disease.

\section{Conclusion}

From the study it was observed that pregnant women visiting Irrua Specialist Teaching Hospital were not affected by Trichomonas vaginalis.

\section{Recommendations}

1. Health education about the causes and mode of transmission of Trichomonas vaginalis must continually be encouraged.

2. Avoidance of multiple sex partners, and indiscriminate sex habit.

3. The use of condoms when having sex.

4. Improved personal care and hygiene.

5. Periodic screening.

6. Adequate treatment with if infected.

\section{References}

[1]. Adu-Sarkodie, Y., Opoku, B.K., Crucitti, T., Weiss, H.A. and Mabey, D. (2007): Lack of evidence for the involvement of rectal and oral trichomonads in the aestiology of vaginal trichomoniasis in Ghana. Sex Transm Infect. 83(2):130-132.

[2]. Alcamo, I.E. (2000): Trichomonas vaginalis. In: Fundamentals of microbiology. Jones and Bartlett Publishers, Boston. Pp. 486-487.

[3]. Ashwood, E.R. (1992): Evaluating Health Maturation of Unborn: the role of the clinical laboratory. Journal of Clinical Chemistry. 38: 883-887.

[4]. Benchimol, M. (2004): Trichomonads under microscopy. Microsc Microanal. 10(5):528-550.

[5]. Burtis, C.A., Ashwood, E.R. and Bruns, D.E. (2OO6): Trace elements. In: Tietz Textbook of clinical Chemistry and Molecular Diagnostics. Saunders. Elsevier Inc., Pp 496-507.

[6]. Carlton, J.M. (2007): Draft genome sequence of the sexually transmitted pathogen Trichomonas vaginalis. Science. 315 (5):207212.

[7]. Carr, B.R. (1998): Pregnancy. In: Textbook of reproductive medcine. Stamford, C.T. (ed.). Appleton \& Lange, USA. Pp 231-239.

[8]. Centers for Disease Control and Prevention (2006): Sexually Transmitted Diseases Treatment Guidelines. MMWR. 55(11):1-94.

[9]. Chamberlain, G. (1998): Clinical Physiology in Obstertrics. In: Texbook of Obstetrics, Blackwell Science, Oxford, London. Pp: $450-478$.

[10]. Chard, T., and Lifford, R. (1998): Pregnancy. In: Sciences for Obstetrics and Gynaecology. Spinger, London. Pp 67-78.

[11]. Crosby, R., DiClemente, R.J. and Wingwood, G.M. (2002): Predictions of infection with Trichomonas vaginalis: a prospective study of low -income African-American adolescent females. Sexually Transmitted Infectection, 78: 360-364.

[12]. Crucitti, T., Abdellati, S., Ross, D.A., Changalucha, J., Dyck, E. and Buve, A. (1991): Detection of Pentatrichomonas hominis DNA in biological specimens by PCR. Int J Fertil. 42: 212-217.

[13]. Dazo, B.C and Biles, J.E. (1974). Two new field techniques for detection and counting of trichomonas vaginalis trophozoit in urine sample with an evaluation of both method Bulletin of world health organization 51:399-408.

[14]. Diamond, L.S. (1986): In vitro cultivation of the trichomonadide: a state of the art review. Acta Univ Caroline - Biol. 30: 221-228.

[15]. Gookin J.L, Birkenheuer, A.J., St John, V., Spector, M. and Levy, M.G. (2005): Molecular characterization of trichomonads from feces of dogs with diarrhea. J Parasitol. 91(4): 939-943. 
[16]. Gopalkrishnan, K., Hinduja, I.N. and Kumar, T.C. (1990): Semen characteristics of asymptomatic males affected by Trichomonas vaginalis. J In Vitro Fert Embryo Transf. 7(3):165-167.

[17]. Heine, P., and McGregor, J.A. (1993): Trichomonas vaginalis: a reemerging pathogen. Clin Obstet Gynecol. 36(1): 137-144.

[18]. Hesseltine, H. (1942): Experimental human vaginal trichomoniasis. J Infect Dis. 71:127.

[19]. Hobbs, M.M., Lapple, D.M, Lawingm, L.F., Schwebke, J.R., Cohen, M.S., Swygard, H., Atashili, J., Leone, P.A., Miller, W.C. and Seña, A.C. (2006): Methods for detection of Trichomonas vaginalis in the male partners of infected women: implications for control of trichomoniasis. J Clin Microbiol. 44(11): 394-399.

[20]. Hook, E.W. (1999): Trichomoniasis III. Sexually Transmitted Diseases, 26: $288-389$. Huppert, J.S., Mortensen, J.E., Reed, J.L., Kahn, J.A., Rich, K.D., Miller, W.C. and Hobbs, M.M. (2007): Rapid antigen testing compares favorably with transcription-mediated amplification assay for the detection of Trichomonas vaginalis in young women. Clin Infect Dis. 45(2):194-198.

[21]. Keith, L.G., Friberg, J., Fullan, N., Bailey, R. and Berger, G.S. (1986): The possible role of Trichomonas vaginalis as a "vector" for the spread of other pathogens. Int J Fertil. 31(4):272-277.

[22]. Krieger, J.N., Tam, M.R. and Stevens, C.E. (1998): Detection of trichomoniasis. JAMA, 269: 1223-1227.

[23]. Krieger, J.N., Jenny, C., Verdon, M., Siegel, N., Springwater, R., Critchlow, C.W. and Holmes, K.K. (1993): Clinical manifestations of trichomoniasis in men. Ann Intern Med. 118(11):844-849.

[24]. Laga, M., Manoka, A. and Kivuvu, M. (2000): Non-ulcerative sexually transmitted diseases risk factors for HIV-1 transmission in women: results from a cohort study. AIDS, 7: 95-102.

[25]. Lanceley, F. and McEntegart, M.G. (1953): Trichomonas vaginalis in the male; the experimental infection of a few volunteers. Lancet.1(14):668-671.

[26]. Lawing, L.F., Hedges, S.R. and Schwebke, J.R. (2000): Detection of trichomoniasis in vaginal and urine specimens from women by culture and PCR. Journal of Clinical Microbiology, 38: 3585-3588.

[27]. Lobo, T.T., Feijó, G., Carvalho, S.E., Costa, P.L., Chagas, C., Xavier, J. and Simoes-Barbosa, A. (2003): A comparative evaluation of the Papanicolaou test for the diagnosis of trichomoniasis. Sex Transm Dis. 30(9): 694-699.

[28]. Lossick, J.G. and Kent, H.L. (1991): Trichomoniasis: trends in diagnosis and management. Am J Obstet Gynecol. 165(4): $217-222$.

[29]. Mackay, E.V., Beisher, N.A. and Pepperell, A.A. (1996): In: Illustrated Textbook for Gyneacology, $2^{\text {nd }}$ edition, W.B. Saunders Co., Philadelphia. Pp. 115-128.

[30]. Schwebke, J.R. and Burgess, D. (2004): Trichomoniasis. Clin Microbiol Rev. 17(4):794-803.

[31]. Schwebke, J.R. and Hook, E.W. (2003): High rates of Trichomonas vaginalis among men attending a sexually transmitted diseases clinic: implications for screening and urethritis management. J Infect Dis. 188(3):465-468.

[32]. Skerk, V., Schönwald, S., Krhen, I., Markovinovic, L., Beus, A., Kuzmanovic, N.S., Kruzic, V. and Vince, A. (2002): Aetiology of chronic prostatitis. Int J Antimicrob Agents.19(6):471-474.

[33]. Sutton, M., Sternberg, M., Koumans, E.H., McQuillan, G., Berman, S. and Markowitz, L. (2007): The prevalence of Trichomonas vaginalis infection among reproductive-age women in the United States, 2001-2004. Clin Infect Dis. 45(10):1319-1326.

[34]. Swygard, H., Sena, A.C. and Hobbs, M.M. (2004): Trichomoniasis: Clinical Manifestations, diagnosis and Management. Sexually Transmitted Infections, 80: 71-95.

[35]. Thomason, J.L. and Gilbert, S.M. (2003): Trichomonas vaginalis. Obstet Gynecol Clin Nor Am., 16: 531-540.

[36]. Wang, C.C., McClelland, R.S., Reilly, M., Overbaugh, J., Emery, S.R., Mandaliya, K., Chohan, B., Ndinya-Achola, J., Bwayo, J. and Kreiss, J.K. (2001): The effect of treatment of vaginal infections on shedding of human immunodeficiency virus type 1. J Infect Dis. 183(7):1017-1022.

[37]. Weinstock, H., Berman, S. and Cates, W. Jr. (2004): Sexually transmitted diseases among American youth: incidence and prevalence estimates. Perspect Sex Reprod Health. 36(1): 6-10. 